AUTHOR CORRECTION OPEN

\title{
Author Correction: GePMI: a statistical model for personal intestinal microbiome identification
}

Zicheng Wang ${ }^{1}$, Huazhe Lou $^{2}$, Ying Wang ${ }^{3}$, Ron Shamir ${ }^{4}$, Rui Jiang ${ }^{1}$ and Ting Chen ${ }^{2}$

npj Biofilms and Microbiomes (2018)4:28; doi:10.1038/s41522-018-0071-4

Correction to: $n p j$ Biofilms and Microbiomes https://doi.org/ 10.1038/s41522-018-0065-2, Published online 04 September 2018

In the original version of this Article some funding information was missing from the Acknowledgements. This has now been corrected in the PDF and HTML versions of the Article.

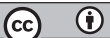

Open Access This article is licensed under a Creative Commons Attribution 4.0 International License, which permits use, sharing, adaptation, distribution and reproduction in any medium or format, as long as you give appropriate credit to the original author(s) and the source, provide a link to the Creative Commons license, and indicate if changes were made. The images or other third party material in this article are included in the article's Creative Commons license, unless indicated otherwise in a credit line to the material. If material is not included in the article's Creative Commons license and your intended use is not permitted by statutory regulation or exceeds the permitted use, you will need to obtain permission directly from the copyright holder. To view a copy of this license, visit http://creativecommons. org/licenses/by/4.0/.

(c) The Author(s) 2018

${ }^{1}$ MOE Key Laboratory of Bioinformatics and Bioinformatics Division, BNLIST and Department of Automation, Tsinghua University, 100084 Beijing, China; ${ }^{2}$ Bioinformatics Division, BNLIST and Department of Computer Science and Technology, Tsinghua University, 100084 Beijing, China; ${ }^{3}$ Department of Automation, Xiamen University, 361005 Fujian, China and ${ }^{4}$ Blavatnik School of Computer Science, Tel-Aviv University, Tel Aviv, Israel

Correspondence: Rui Jiang (ruijiang@tsinghua.edu.cn) or Ting Chen (tingchen@mail.tsinghua.edu.cn)

Published online: 07 November 2018 